\title{
Differentiatie in de huisartsopleiding: evaluatie van een nieuwe module
}

\author{
M.H. Sagasser • Th.B. Voorn • B.P.A. Thoonen • B.J.A. \\ M. Bottema - Th.B. Voorn • B.P.A. Thoonen
}

Samenvatting Inleiding: Aan het derde jaar van de huisartsopleiding is de keuzemodule 'Differentiatie' toegevoegd. Met deze curriculumvernieuwing wordt beoogd de huisarts-in-opleiding (aios) maatwerk te bieden tijdens de opleiding en een aanzet te geven voor een persoonlijke ontwikkeling in de latere beroepspraktijk. Voor deze module stelt de aios bij een zelfgekozen differentiatie- onderwerp een plan op met doelen, activiteiten en tijdsbesteding. In een evaluatiestudie zijn de meningen van aios, huisarts-opleiders (hao's) en docenten over de praktische uitvoering onderzocht.

Methode: Aan twee cohorten derdejaars aios van de Voortgezette Opleiding tot Huisarts (VOHA) van het UMC St. Radboud in Nijmegen, en aan de betreffende hao's en docenten, zijn vragenlijsten voorgelegd met gesloten (5-puntsschaal) en open vragen. De scores van de gesloten vragen zijn gewaardeerd als positief, negatief, neutraal, verdeeld of divers. De antwoorden op de open vragen zijn geclusterd.

Resultaten: Alle respondenten zijn positief over het bereikte resultaat en over de uitvoeringsmogelijkheden van de differentiatie. Competenties zijn toegenomen en aios zijn gemotiveerd zich verder in het onderwerp te verdiepen. Enthousiasme voor het onderwerp en een enthousiaste hao worden belangrijk gevonden voor een succesvolle differentiatie. Wel is er onduidelijkheid over de opzet van de differentiatie, de begeleiding van de docent en de functie van de 'terugkomdag'.

Discussie en conclusies: Ondanks de onduidelijkheid zijn aios, hao's en docenten positief over het eindresultaat. De differentiatie kan verbeterd worden door de

M.H. Sagasser ( $\varangle)$

Mw. drs. M.H. Sagasser, C St Radboud, HA 166, stbus 9101, 00 HB Nijmegen. Tel.: 024-3615300; email: g.sagasser@voha. umcn.nl Correspondentieadres:

mogelijkheden van het leren in de praktijk te versterken. Docenten moeten meer ondersteund worden in het vertalen van de doelen naar onderwijs- en begeleidingsactiviteiten. Discussie is nodig over de vraag welke activiteiten de aios zelf uitvoert en in welke activiteiten het instituut faciliteert. (Sagasser MH, Voorn ThB, Thoonen BPA, Bottema BJAM. Differentiatie in de huisartsopleiding: evaluatie van een nieuwe module. Tijdschrift voor Medisch Onderwijs 2007;26(6):279-287.)

\section{Inleiding}

De huisartsopleidingen in Nederland hebben in 2004 een curriculumherziening ingevoerd. ${ }^{1-2}$ In het derde en tevens laatste opleidingsjaar is de keuzemodule 'Differentiatie' opgenomen. Deze differentiatie is bestemd voor een inhoudelijke verdieping, gebaseerd op een persoonlijke keuze van de huisarts-in-opleiding (aios). Deze keuzemodule binnen de opleiding kan de aanzet zijn tot een persoonlijke ontwikkeling in de latere beroepspraktijk. Het differentiatie- onderwerp moet relevant zijn voor de huisartsgeneeskundige zorg en de verkregen extra deskundigheid of vaardigheid moet ook implementeerbaar zijn in de huisartsenpraktijk. Deze keuzemodule creëert zo huisartsen met extra deskundigheid in een bepaald onderdeel van het huisartsenvak.

Differentiatie van taken binnen een huisartsenpraktijk is één van de speerpunten in de toekomstvisie van het Nederlands Huisartsen Genootschap (NHG) en van de Landelijke Huisartsen Vereniging (LHV) ten aanzien van de huisartsenzorg. ${ }^{3-4}$ De keuzemodule 'Differentiatie' kan een stimulans betekenen voor deze door de beroepsgroep wenselijk geachte ontwikkeling. In het landelijke 
Raamplan (2001) zijn, behalve tijdsduur en soort onderwerpen, geen richtlijnen gegeven voor de inrichting van de module.

Bij de Voortgezette Opleiding tot Huisarts (VOHA) van het UMC St. Radboud in Nijmegen is een commissie ingesteld die lokaal de differentiatie heeft vormgegeven. ${ }^{5}$ De doelen van de differentiatie zijn door de commissie als volgt geformuleerd:

1. De aios heeft zijn competentie verbreed of verdiept op een klinisch deelgebied of op een ander voor de huisartsgeneeskunde relevant deelterrein.

2. De aios kan aangeven hoe deze extra competentie als specialisatie/ differentiatie benut kan worden binnen een groepspraktijk/huisartsengroep.

3. De aios heeft vaardigheden ontwikkeld om een differentiatie daadwerkelijk in de praktijk vorm te geven.

De keuzemodule 'Differentiatie' bestaat uit een combinatie van externe stage(s), activiteiten in de stage-huisartsenpraktijk, ondersteunend ('terugkomdag') onderwijs en zelfstudie. De aios kan kiezen voor onderwerpen als astma/COPD, hart- en vaatziekten, maar ook voor palliatieve zorg, onderwijs en praktijkmanagement. Conform de uitgangspunten van het nieuwe curriculum heeft de VOHA ervoor gekozen om de aios veel mogelijkheden tot zelfsturing te geven. De aios stelt zelf een differentiatieplan op dat aan bepaalde criteria moet voldoen. In het plan legt de aios vast welke competenties behaald gaan worden, welke activiteiten nodig zijn om deze competenties te verwerven, waar dat binnen de opleidingspraktijk en extern (bijvoorbeeld stages, trainingen) gebeurt, en welke zelfstudie nodig is. In het plan neemt de aios een tijdpad op. Zonodig krijgt de aios ondersteuning bij de keuze van het onderwerp en bij het opstellen van het differentiatieplan. Ter afsluiting van de keuzemodule schrijft de aios een verslag en presenteert het resultaat van de differentiatie voor de eigen aios-groep. Tijdens de keuzemodule krijgt de aios begeleiding van de huisarts-opleider (hao) en van de twee docenten die de aios-groep begeleiden. De keuzemodule heeft een nominale tijdsduur van drie maanden en wordt gespreid over het derde opleidingsjaar uitgevoerd.

Ten behoeve van de organisatie van de module is een differentiatiecoördinator aangesteld. Om aios, docenten en hao's te informeren over het doel, de organisatie en de werkwijze in de keuzemodule is informatie zowel mondeling als schriftelijk verspreid in de aios- c.q. hao-groepen en via de elektronische leeromgeving. Daarnaast is de differentiatiecoördinator een aantal keren in de aios/ hao-groepen geweest om eventuele vragen te beantwoorden. Tevens was er gelegenheid om direct vragen te stellen aan de differentiatiecoördinator (telefonisch en via vragenuur, e-mail en Blackboard).
Tijdens de voorbereiding van deze module werd duidelijk dat er in de context van de differentiatie een aantal mogelijke barrières waren, te weten:

1. Zelfwerkzaamheid: er wordt een groot beroep gedaan op de zelfwerkzaamheid van de aios. Het is voor het eerst dat de aios bij een omvangrijk onderdeel als de differentiatie deze rol heeft. Daarmee is de aios een belangrijke factor in het slagen van de differentiatie.

2. Lange looptijd: de differentiatie wordt, ingebed in een ander onderwijsonderdeel, over langere looptijd uitgevoerd.

3. Concurrerende activiteiten: het derde opleidingsjaar wordt ervaren als een vol en zwaar jaar met veel concurrerende activiteiten, waardoor de differentiatie mogelijk niet de aandacht krijgt die nodig is.

4. Verplicht onderdeel: hoewel er binnen de differentiatie keuzemogelijkheden zijn, is de differentiatie een verplicht onderdeel, terwijl niet iedere aios daar behoefte aan heeft.

Daar de differentiatie een nieuw onderwijsonderdeel is binnen de huisartsopleiding, is met deze evaluatie onderzocht of, gegeven de context, de doelen van de differentiatie bereikt zijn en welke barrières ervaren zijn.

\section{Vraagstellingen van de evaluatie}

Het doel van de evaluatie is om antwoord te krijgen op de volgende vraagstellingen:

1. Wat is de mening van de aios, hao's en docenten over de mate waarin de aios competenties verwerven over het gekozen onderwerp?

2. Wat is de mening van de aios, hao's en docenten ten aanzien van het bereikte resultaat en de leerzaamheid, de duidelijkheid en de organisatie van de module, en ten aanzien van de uitvoeringsmogelijkheden?

3. In hoeverre worden de aios gemotiveerd zich verder in het onderwerp te willen verdiepen?

4. Wat is de mening van de aios over de begeleiding in een context waarbinnen de aios juist veel zelf moet doen?

\section{Methoden}

Populatie

De evaluatie is uitgevoerd bij de aios die in maart en september 2005 in het derde jaar zijn gestart. Zowel aios, hao's als docenten zijn in de evaluatie betrokken. 


\section{Instrument}

Er zijn vragenlijsten ontwikkeld voor aios, hao's en docenten. De vragenlijsten bestaan uit gesloten vragen (merendeel op 5-puntsschaal, uiteenlopend van 1: zeer oneens tot 5: zeer eens) en open vragen. De vragenlijst voor de aios bestond uit 102 gesloten en zeven open vragen, die voor de hao's uit 55 gesloten en zeven open vragen en die voor de docenten uit 37 gesloten en zeven open vragen. Om de validiteit van de vragen te toetsen zijn de conceptversies van de vragenlijsten voorgelegd aan enkele hao's, docenten en onderwijscoördinatoren. De vragen zijn verdeeld over de volgende thema's:

1. Duidelijkheid: de opzet van de keuzemodule en de taken daarin van de aios, hao en docent.

2. Inhoud en uitvoering: het maken van het plan, de uitvoering, het bereikte resultaat, de beoordeling en de tijdsbesteding.

3. Begeleiding: door hao en docenten.

4. Communicatie: de informatieverstrekking, vooraf en tijdens de keuzemodule, tussen VOHA, docenten, hao en aios.

5. Nut: meningen over leerzaamheid en veronderstelde meerwaarde in de opleiding.

Vijf weken vóór het afronden van de keuzemodule zijn de vragenlijsten elektronisch aan de aios, hao's en docenten aangeboden. De termijn voor het invullen van de vragenlijst was gesteld op drie weken. $\mathrm{Na}$ één en twee weken kregen de non-respondenten een herinnering per e-mail.

\section{Analyse}

Aan elke gesloten vraag is een waarde toegekend:

1. 'positief' betekent dat $50 \%$ of meer van de respondenten score 4 of 5 (positieve waarde) geeft en de scores 1 en 2 (negatieve waarde) samen minder dan 30\% hebben.

2. 'negatief' betekent dat $50 \%$ of meer van de respondenten score 1 of 2 geeft en de scores 4 en 5 samen minder dan $30 \%$ hebben.

3. 'neutraal' betekent dat $50 \%$ of meer van de respondenten score 3 geeft.

4. 'verdeeld' betekent dat alle scores op 4 en 5,1 en 2 , en 3 tussen de 30-50\% liggen.

5. 'divers' betekent dat de scores op 1 en 2 en 4 en 5 tussen de $30-50 \%$ liggen en minder dan $30 \%$ een score 3 geeft.

De scores op de open vragen zijn handmatig gerubriceerd.

\section{Resultaten}

De respons bij de aios is 70\% (60/86), bij de hao's $70 \%$ (58/83) en bij de docenten $92 \%$ (11/12).

\section{Gesloten vragen}

Bij de beschrijving zijn de resultaten van de aios als uitgangspunt genomen. Waar relevant zijn de resultaten van de hao's en docenten in de bespreking betrokken. Het resultaat van een selectie van onderwerpen wordt hier beschreven. In tabel 1 zijn per geselecteerd onderwerp de vragen met hun waarde opgenomen. In kolom 1 staan de vragen van de aios-vragenlijst; in kolom 2 ('aios') staat de door hen toegekende waarde. Indien deze vraag ook aan hao's en/of docenten is gesteld, dan is die waarde in kolom 3 respectievelijk 4 opgenomen. De vraagformulering in de vragenlijst was toegespitst op de betreffende respondenten (bijvoorbeeld 'de differentiatiedoelen van de aios' in plaats van 'mijn differentiatiedoelen').

Uitvoering, begeleiding: de aios zijn positief over het bereikte resultaat en over de uitvoeringsmogelijkheden van de keuzemodule. De hao's en docenten delen dit oordeel. Aios zijn positief over de begeleiding door de hao. De hao's zijn neutraal tot positief over hun eigen begeleiding. Aios zijn echter negatief over de begeleiding van de docenten en over de relevantie van het 'terugkomdag'-onderwijs. Ook de hao's geven aan dat de begeleiding van de docenten beter kan. De docenten zelf zijn ook deze mening toegedaan.

Tijdsbesteding: aios geven aan de doelen binnen de gestelde tijd te behalen. Hao's oordelen hier anders over: een deel vond dat dit wel lukte, een ander deel vond dat dit niet lukte. Zowel aios als hao's menen dat er onvoldoende tijd is om de differentiatie naast alle andere praktijk- en opleidingsactiviteiten uit te voeren. Aios geven aan aanzienlijk minder tijd aan de differentiatie te besteden dan de norm van één dag per week.

Duidelijkheid: over het algemeen was er bij de aios te weinig duidelijkheid over de differentiatie, bijvoorbeeld over de opzet van de keuzemodule, wat van hen verwacht werd en wat zij van anderen konden verwachten. Ook bij docenten speelde dit, zij het in mindere mate. Bij hao's heerste ook veel onduidelijkheid, hoewel de hao's op sommige punten verdeeld zijn.

Elektronische leeromgeving (Blackboard): wat betreft de via de elektronische leeromgeving verspreide informatie vallen de aios in twee groepen uiteen: een groep die de informatie wel wist te vinden, en een groep die dat niet wist. De aios oordelen verdeeld over de elektronische leeromgeving. 
Tabel 1 Overzicht van de vragen per geselecteerd onderwerp met bijbehorende waarde.*

\begin{tabular}{rrr}
\hline & Aios & Hao's Decenten \\
\hline
\end{tabular}

Bereikt resultaat (6 vragen)

Mijn competenties op het gebied van het door mij gekozen differentiatie-onderwerp zijn gegroeid

Ik heb vaardigheden ontwikkeld om een differentiatie daadwerkelijk in de praktijk vorm te geven

Ik ben tevreden met het door mij in de differentiatie bereikte resultaat

Ik vond deze differentiatie leerzaam

Door de differentiatie ben ik gemotiveerd mij nog verder in dit onderwerp te verdiepen

Door de differentiatie heb ik het gevoel een meerwaarde te hebben voor mijn toekomstige werkkring

\section{Uitvoeringsmogelijkheden differentiatie (6 vragen)}

Er waren voldoende mogelijkheden om mijn differentiatie vorm te geven

Er waren voldoende mogelijkheden in de huisartsenpraktijk om differentiatie-activiteiten uit te voeren

De bijdrage van activiteiten in de huisartsenpraktijk aan het behalen van mijn differentiatiedoelen was 1: zeer klein, 5: zeer groot

De bijdrage van externe activiteiten (stages, cursussen e.d.) aan het behalen van mijn differentiatiedoelen was 1: zeer klein, 5: zeer groot

De bijdrage van zelfstudie-activiteiten aan het behalen van mijn differentiatiedoelen was 1: zeer klein, 5: zeer groot

De bijdrage van 'terugkomdag'-activiteiten aan het behalen van mijn differentiatiedoelen was 1: zeer klein, 5: zeer groot

Hao-praktijk en begeleiding hao (4 vragen)

Ik ben tevreden over de begeleiding van de hao

De differentiatie was onderwerp van een leergesprek

Het is een meerwaarde als de hao expertise heeft op het gebied van het differentiatie-onderwerp van de aios

De hao zorgde ervoor dat gestelde vragen over de differentiatie beantwoord werden

'Terugkomdag'-onderwijs en begeleiding docenten ( 3 vragen)

Ik ben tevreden over de begeleiding van de docenten

De docenten zorgden ervoor dat de gestelde vragen over de differentiatie beantwoord werden

De docenten waren goed bereikbaar voor vragen

Tijdsbesteding (6 vragen)

Mijn differentiatiedoelen waren goed te behalen binnen de gestelde tijd

Er was voldoende tijd om de differentiatie-activiteiten naast andere praktijk- en opleidingsactiviteiten uit te voeren

De hoeveelheid tijd besteed aan externe activiteiten was voldoende

De hoeveelheid tijd besteed aan de differentiatie tijdens de 'terugkomdag' was voldoende

De hoeveelheid tijd besteed aan differentiatie in de huisartsenpraktijk was voldoende

De norm is dat gedurende het 3e jaar 1 dag per week aan differentiatie besteed wordt. Hoeveel tijd heeft u, t.o.v. deze norm, besteed aan de differentiatie?

\section{Duidelijkheid - algemeen (5 vragen)}

De doelen van de differentiatie waren duidelijk

Het was mij duidelijk wat van mij als aios werd verwacht

Het was mij duidelijk wat ik van de docenten kon verwachten

Het was mij duidelijk wat ik van de hao kon verwachten

Ik ben tijdig geïnformeerd over de doelen en opzet van de differentiatie

Blackboard (5 vragen)

De hoeveelheid informatie op Blackboard over de opzet, planning, criteria etc., was voldoende

De op Blackboard geplaatste informatie was duidelijk

De instructie voor het werken met Blackboard was duidelijk

Het was duidelijk waar welke informatie op Blackboard te vinden is

Meerwaarde (1 vraag)

De differentiatie heeft een meerwaarde voor de opleiding tot huisarts

* nvt: de vraag is niet aan betreffende groep respondenten gesteld.

$\begin{array}{ccc}\text { verdeeld } & \text { nvt } & \text { nvt } \\ + & + & \text { nvt } \\ + & \text { nvt } & \text { nvt } \\ + & \text { nvt } & \text { nvt } \\ + & \text { nvt } & \text { nvt } \\ + & & \text { nvt }\end{array}$

Neutraal Neutraal

$+$

nvt

Verdeeld

Divers

nvt

- Neutraal

Verdeeld

- Neutraal

Divers

Verdeeld Neutraal

nvt

$+$

Verdeeld

$+$

nvt

$+$

Verdeeld

Verdeeld

nvt

nvt

nvt

nvt

nvt

nvt

$\begin{array}{rll}\text { Verdeeld } & \text { nvt } & \text { nvt } \\ \text { Verdeeld } & \text { nvt } & \text { nvt } \\ \text { Divers } & \text { nvt } & \text { nvt } \\ \text { Divers } & \text { nvt } & \text { nvt }\end{array}$

Verdeeld

$+$

nvt 
Meerwaarde: een ander punt waarover zowel aios als hao's verdeeld zijn is de meerwaarde van de differentiatie voor de opleiding tot huisarts. Dit in tegenstelling tot de docenten die hier juist positief over zijn.

\section{Open vragen}

Positieve aspecten: uit de beantwoording van de open vragen blijkt dat aios het opdoen van kennis en ervaring en het verdiepen in een specifiek gebied het meest leerzaam vinden. Daarnaast wordt ook het leren en toepassen in de praktijk (bijvoorbeeld in de huisartsenpraktijk of tijdens stages) gewaardeerd. Een aantal aios vindt het leerzaam dat zij hun eigen weg moeten zoeken.

Op de vraag wat de differentiatie goed uitvoerbaar maakte komt vooral affiniteit met het onderwerp naar voren, betrokkenheid van de hao en medewerking van stageverleners. Ook kwam naar voren dat de vrijheid om een eigen plan te maken de differentiatie ten goede kwam. De hao's zijn van mening dat de motivatie van de aios het belangrijkste is. De docenten noemen zowel de motivatie van de aios als die van de hao. De hao's noemen tevens nog de mogelijkheden die de praktijk biedt voor de uitvoering van de differentiatie.

Verbeterpunten: op de vraag wat de differentiatie bemoeilijkte is door veel aios de onduidelijkheid genoemd; ook de hao's en docenten geven dit aan. Tijdgebrek en slechte begeleiding zijn vaak genoemd alsook het ontbreken van feedback.

Op de vraag wat de aios een volgende keer anders zou doen wat betreft het te kiezen onderwerp wordt gezegd: hou het klein, kies een onderwerp dat bij je past, dat relevant is in de huisartsenpraktijk, en dat uitvoeringsmogelijkheden heeft in die praktijk. Docenten benadrukken het belang van een goede organisatie van de keuzemodule, goede (individuele) begeleiding, aandacht op de 'terugkomdag', adequate begeleiding van hao's, en dergelijke. Een groot aantal hao's is òf van mening dat de differentiatie niet in de opleiding hoort, ò dat het er wel in hoort maar op een andere plaats binnen de opleiding.

\section{Discussie en conclusies}

Aios, hao's en docenten zijn positief over het eindresultaat: competenties ten aanzien van het differentiatieonderwerp zijn naar de mening van de ondervraagden toegenomen en aios zijn gemotiveerd zich verder in het onderwerp te gaan verdiepen. Hierbij moet wel de kanttekening geplaatst worden dat in deze evaluatie geen uitspraak is gedaan over de kwaliteit van het eindresultaat, maar dat het oordeel van de hao's en docenten hierin meetelt. De keuzemodule 'Differentiatie' lijkt de motivatie van de aios te versterken om hun interessegebied verder te exploreren, en er mogelijk ook na de opleiding mee verder te gaan. De praktijk levert voldoende mogelijkheden om te differentiëren, en de opleider speelt hierbij een belangrijke rol.

De 'terugkomdag' en de docenten kregen geen positieve waardering. Ondanks het feit dat de docenten de doelen duidelijk vonden, is het niet gelukt deze te vertalen naar een adequate invulling van de 'terugkomdag' en begeleiding. De docenten moeten hierin meer ondersteund worden.

Wat verder opvalt is dat de aios veel minder tijd aan de differentiatie besteed hebben dan de norm die ervoor stond. Dit heeft mogelijk te maken met het feit dat de differentiatie nieuw was, de gewenste tijdsinvestering onduidelijk en dat andere onderdelen in het derde jaar ook (veel) tijd van de aios vereisten. Aios geven aan dat er veel tijd verloren ging aan het regelen van allerlei organisatorische zaken. Ondanks het feit dat het leerzaam is te ervaren wat er allemaal komt kijken bij bijvoorbeeld het regelen van een stageplaats, moet men zich afvragen of dat een doel van de differentiatie is of dat de tijd efficiënter besteed kan worden aan meer inhoudelijke doelen.

De aios hebben niet veel waardering voor de opzet van de differentiatie. Hoewel er veel informatie (o.a. via Blackboard) beschikbaar was, en er op diverse momenten en via diverse kanalen gelegenheid tot het stellen van vragen, is er veel onduidelijkheid geweest over de opzet van de module, wat van de aios verwacht werd en wat zij van anderen konden verwachten.

Vanaf de invoering van de differentiatie zijn er weerstanden gesignaleerd bij aios, docenten en hao's, met een negatieve sfeer als resultaat. Uit de evaluatie blijkt dat de weerstand vooral te maken heeft met het feit dat het een nieuw onderdeel was waarbij een grote zelfstandige rol van de aios werd verwacht. Daarnaast speelt mee dat het opleidingsjaar waarin de differentiatie is ingevoerd door aios als vol en zwaar wordt ervaren. De inspanningen die geleverd zijn om de betrokkenen te instrueren over de differentiatie hebben deze weerstanden niet voldoende kunnen wegnemen.

Wat betreft de evaluatiemethode zijn er ook nog een aantal punten die de resultaten beïnvloed kunnen hebben. Ten eerste kan de lengte van de vragenlijst demotiverend gewerkt hebben. De vragenlijst lijkt lang door het grote aantal items. De elektronisch afname van deze lijst maakte het mogelijk dat de aios binnen een periode van drie weken zelf het tijdstip van invullen konden kiezen waardoor de kans aanwezig was dat de lijst helemaal niet meer werd ingevuld. Het voordeel van de elektronische afname was de snelle beschikbaarheid van de gegevens en snelle communicatie met respondenten. De respons van 
minimaal $70 \%$ is voldoende groot om van representatieve gegevens te kunnen spreken en geeft voldoende inzicht in de meningen van aios, hao's en docenten.

Samengevat wordt de differentiatie positief gewaardeerd wat betreft de inhoud en de uitvoeringsmogelijkheden in de praktijk en kan er winst geboekt worden door:

1. meer structuur aan te brengen op punten waar onnodig veel tijd en energie verloren gaat aan bijvoorbeeld praktische zaken.

2. mogelijkheden tot leren in de praktijk te versterken.

3 . de benodigde begeleiding door docenten en de mogelijkheden op de 'terugkomdag' verder uit te werken naar herkenbare coaching en feedback, passend bij een competentiegericht en zelfsturend leertraject.

Deze evaluatie heeft een aantal punten aan het licht gebracht waarop de differentiatie verbeterd kan worden. Deze resultaten hebben een rol gespeeld bij de landelijke discussie over de differentiatie. ${ }^{6-7}$ Eén van de discussiepunten blijft de mate van zelfsturing door de aios. Voor een opzet waarbij de aios minder zelfsturing heeft, zoals bij een vast omschreven aanbod van cursussen waaruit de aios kan kiezen, is bewust niet gekozen. De VOHA vindt het zeer waardevol en passend binnen het competentiegericht opleiden dat de aios zelf keuzes maakt in het formuleren van leerdoelen, het kiezen van leeractiviteiten en toetsingen.

Een opbrengst van de landelijke discussie is dat de differentiatie nu een facultatieve module is. ${ }^{6}$ Tijdens het eerste opleidingsjaar maakt de aios een keuze voor het differentiatie-onderwerp. Gedurende het tweede jaar bereidt de aios de differentiatie theoretisch voor. Tijdens het derde jaar voert de aios de differentiatie praktisch uit in de opleidingspraktijk. Ook in deze opzet van de differentiatie stelt de aios zelf een differentiatieplan op met uit te voeren activiteiten en tijdsbesteding. De in deze evaluatie gevonden verbeterpunten zijn goed inpasbaar in de nieuwe opzet van de differentiatie. De enquête heeft waardevolle informatie opgeleverd voor de verdere invulling van de differentiatie, zowel landelijk als bij de VOHA.

Belangenconflict: geen gemeld.

Financiële ondersteuning: geen gemeld.

\section{Summary}

Introduction: An elective module promoting differentiation was introduced in Year 3 of the recently revised postgraduate training programme in general practice in the Netherlands. The module enables trainees to pursue a topic of their own choice as the start of continued development of this interest after postgraduate training. Trainees design a learning plan focused on specific competencies, learning activities and a time schedule. The opinions of GP trainees, GP trainers and teachers were sought to evaluate the module.

Method: Questionnaires containing closed (five-point Likert scale) and open-ended questions were sent to two cohorts of GP trainees in Year 3 and GP trainers and teachers of the Department for Postgraduate training General Practice, Radboud University Nijmegen Medical Centre. The closed questions resulted in rating as positive, negative, neutral, divided or miscellaneous. The answers to the open-ended questions were categorised.

Results: All respondents were satisfied with the learning results and the learning opportunities related to the module. Trainees' competencies had increased and trainees were motivated to further pursue their selected topics. Success of the module was enhanced by trainees' and trainers' enthusiasm about topics. Confusion existed about the organisation of the module, coaching by the teachers and the function of the training days at the Institute of General Practice.

Discussion and conclusions: Despite some confusion, there was general satisfaction with the Differentiation module. Increased opportunities for practice-based training might be beneficial. Teachers might benefit from help in translating educational goals to educational and coaching activities. Discussion should focus on which activities should be self directed by trainees and which ones should be facilitated by the Institute of General Practice. (Sagasser MH, Voorn ThB, Thoonen BPA, Bottema BJAM. Differentiation in postgraduate training for general practice: evaluation of a new module. Dutch Journal of Medical Education 2007;26(6):279-287.)

\section{Literatuur}

Raamplan Huisartsopleiding, Werkgroep Raamcurriculum, Utrecht; april 2001.

Raamplan Huisartsopleiding, samenvatting. PVH, Utrecht; maart 2003.

Huisartsenzorg en Huisartsenvoorziening. Concretisering Toekomstvisie 2012. Rapport van de werkgroep Functie- en Taakomschrijving Huisartsenzorg. LHV/NHG; 2003.

Toekomstvisie huisartsenzorg. NHG, 2002.

Blok 8: Differentiatie. Blok 8-commissie, VOHA, Nijmegen; juni 2004.

Raamcurriculum 2005, SVUH, Utrecht; november 2005.

Differentiatie in de huisartsopleiding, PVH, Utrecht; januari 2006. In: Handreiking voor een Opleidingsplan (HOP), Richtsnoer bij raamcurriculum 2005, PVH, Utrecht; maart 2006. 